\title{
Green Nanosilicas for Monoaromatic Hydrocarbons Removal from Air
}

\author{
Abdunaser M. Ewlad-Ahmed ${ }^{1} \cdot$ Michael Morris $^{2} \cdot$ Justin Holmes $^{3} \cdot$ David J. Belton $^{4} \cdot$ Siddharth V. Patwardhan $^{5}$ (D) \\ Lorraine T. Gibson ${ }^{1}$
}

Received: 16 September 2020 / Accepted: 22 December 2020 / Published online: 22 January 2021

(C) The Author(s) 2021

\begin{abstract}
We demonstrate a novel application of green nanosilicas (GN), prepared via an environmentally friendly route, in removing volatile organic compounds (VOCs). Herein, we aim to establish GN as viable alternatives to traditional mesoporous silicas for the removal of monoaromatic hydrocarbons (MAHC). The results show that the GN have high extraction efficiencies comparable to those previously reported for mesoporous silicas. It was demonstrated that bespoke GN can be syntheised readily with the ability to tailor their physical properties and MAHC adsorption. In order to understand the MAHC adsorption by GN, their porosity, morphology and pore structure were characterised. It was observed that the combination of broad pore size distribution and, in particular, the presence of meso- and micro-porosity in GN contributed to high MAHC extraction efficiencies and selectivity. Although from a commercial viewpoint, further optimisation of GN is desirable in order to replace traditional sorbents, this work clearly highlights a new family of "green" sorbents, which can be prepared with a substantial reduction in secondary pollution with potential applications in selective gas separation.
\end{abstract}

Keywords VOC $\cdot$ Biosilica $\cdot$ Microporosity $\cdot$ Adsorbent $\cdot$ Mesosilica $\cdot$ Air pollution

\section{Introduction}

Porous materials are used in wide ranging applications such as catalysis, separations, detergents, biomedical devices, chemical sensors, electronic devices and many emerging technologies $[1,2]$. Inorganic porous materials have been extensively employed due to their strong resistance to extreme conditions that are typically encountered in catalysis and separations such as elevated temperatures, high pressures and chemical attack

Siddharth V. Patwardhan

s.patwardhan@sheffield.ac.uk

$\triangle$ Lorraine T. Gibson

lorraine.gibson@strath.ac.uk

1 Department of Pure and Applied Chemistry, WestCHEM, University of Strathclyde, 295 Cathedral Street, Glasgow G1 1XL, UK

2 AMBER Research Centre, Trinity College, Dublin, Ireland

3 Department of Chemistry, University College Cork, Cork, Ireland

4 School of Science and Technology, Nottingham Trent University, Clifton Lane, Nottingham NG11 8NS, UK

5 Department of Chemical and Biological Engineering, University of Sheffield, Mappin Street, Sheffield S1 3JD, UK
$[3,4]$. Recent literature has highlighted the widespread applications of mesoporous silica - an important class of inorganic porous materials - for use in industrial, technological or domestic applications [5-7]. The popularity of inorganic porous materials, especially mesoporous silica, is due to their unique properties: well-defined, uniform and tunable pores, and ease of "moulding" into nanoparticles, films and monoliths [8]. Extensive research has been conducted to tailor textural properties of silica including surface area, pore volume, pore-size distribution or surface chemistry [5-7, 9-12], resulting in ordered mesoporous materials such as Mobil Crystalline Materials (MCM-41) or Santa Barbara Amorphous materials (SBA-15) [13-16].

MCM-41, with hexagonally arranged cylindrical mesopores, large surface area and narrow pore size distribution, has arguably attracted the most attention of the scientific community with uses in adsorption, separation, catalysis, or environmental pollution control [5-7]. For example, porous materials are used in a variety of environmental remediation applications such as the removal of toxic chemicals from air, in particular, volatile organic compounds (VOCs), which can cause asthma or cancer [17]. These include monoaromatic hydrocarbons (MAHC) such as benzene, toluene, ethylbenzene, and dichlorobenzene as important VOCs that are 
released from building materials such as wood-based products, paints, gypsum, floor finishes, glues, carpets, household solvents, air fresheners and office equipment and, in addition, human activities such as cleaning products, cooking and tobacco smoking [18-21]. A variety of methods are currently used to improve air quality such as the use of porous sorbents in the heating, ventilation and air conditioning (HVAC) systems [22]. To date, most commercial products pertaining to VOC removal are based on polymers or porous carbons (e.g. Tenax $^{\text {TM }}$ TA, Carbotrap $®$, Porapak ${ }^{\circledR}$ and Carboxen $\left.{ }^{\circledR}\right)$. However, recent research has shown that mesoporous silicas such as MCM-41 are very efficient scavengers of larger VOCs like MAHC when compared with industrial standards such as Tenax ${ }^{\text {TM }}$ TA $[18,23]$. Aromatic molecules such as benzene and toluene have shown strong interactions with silica surfaces [24] and with the ability to tune textural properties of porous silicas, VOC adsorption can be improved [25]. Furthermore, silicas can be readily tailored by chemical modification to target specific VOCs or conditions. Indeed, a recent review has concluded that functionalised mesoporous silicas are rapidly establishing as promising adsorbents for VOC capture [26]. However, these materials are generally prepared under harsh conditions and require long procedures, e.g., elevated temperature, high pressure, strongly alkaline or acidic solutions with preparations taking several days [27-29]. Another major drawback of these materials is the environmentally damaging conditions/ chemicals involved in their production, leading to secondary pollution - this only shifts the pollution removal problem. It is therefore clear that greener alternatives to such porous materials are required.

It appears that diatoms (microalgae) produce large quantities of porous, hierarchically ordered and nanostructured biosilica, entirely under environmentally friendly conditions with remarkable regulation, which is achieved by the use of biomolecules (e.g. proteins, polysaccharides and small amines) [28-31]. The understanding of the roles these biomolecules play in vivo has led to the invention of in vitro bioinspired silica synthesis processes that adopt mild (green) conditions by utilising analogues of biomolecules, called "additives" [30, 31]. Of particular importance here for gas separation is the ability of certain additives to control the porosities of GN silicas, which potentially could have an impact on selective adsorption that is typically required in VOC removal $[32,33]$. The synthesis of GN takes $5-15 \mathrm{~min}$ at neutral $\mathrm{pH}$ in water and room temperature in contrast to $10-148 \mathrm{~h}$ required for traditional mesoporous silica synthesis under highly acidic conditions in a co-solvent (typically an alcohol) at elevated temperatures (or lengthy procedures if performed at low temperatures).

Utilising this knowledge, we have recently tested one GN for the extraction of formaldehyde vapour from contaminated indoor air [34]. The material was shown to provide an excellent alternative to conventional mesoporous silicas but without the attendant secondary pollution that is often encountered, however, that paper reported the observations from only one sample, as a brief comparison. In this study, we aim to systematically evaluate $\mathrm{GN}$ as viable alternatives to traditional mesoporous silicas such as MCM-41 for the removal of monoaromatic hydrocarbons. We aim to go significantly beyond our proof-of-concept results from formaldehyde removal and as such, this work represents advancement in the following ways. Formaldehyde and monoaromatic hydrocarbons (MAHC) are two distinct groups of molecules with different polarities and hence their adsorption mechanisms are vastly different. Formaldehyde is known to follow chemisorption (e.g. requires amine functionalisation) while MAHC adsorb via physisorption, which depends on the particular size and arrangement of pores. This requires greatly different strategies for their separation - we aim to understand these mechanisms and design suitable GN by performing an in depth study devoted to tailoring the performance of bioinspired silicas through synthetic strategies. Finally, a mechanistic understanding of the performance of bioinspired silica achieved through extensive materials characterisation is presented.

\section{Experimental}

\subsection{Chemicals \& Reagents}

Sodium metasilicate $\left(\mathrm{Na}_{2} \mathrm{SiO}_{3} .5 \mathrm{H}_{2} \mathrm{O}\right)$, hydrochloric acid $(\mathrm{HCl})$ and toluene were obtained from Fisher Scientific; pentaethylenehexamine (PEHA) and cumene were supplied by ACROS ORGANICS, and Sigma Aldrich supplied ethylbenzene and dichlorbenzene. All chemicals were used as supplied without any sample pre-treatment.

\subsection{Synthesis of GN}

The GN materials were synthesised by modifying a previously published method [34-36] as described briefly below. Sodium metasilicate was used as a silica source and PEHA was used as the additive. To a neutralised solution of sodium metasilicate in deionized water, aqueous solution of PEHA was added. If required, the $\mathrm{pH}$ of this mixture was immediately adjusted to $\mathrm{pH} 7 \pm$ 0.1 by adding a few drops of $1 \mathrm{M} \mathrm{HCl}$ and rapid precipitation of silica was visible within one min. The resultant precipitate was collected after $15 \mathrm{~min}$ by filtration, washing three times with deionized water, and drying in air at room temperature. In order to allow clear comparison with the literature reporting mesopores silica, the samples were calcined at $500{ }^{\circ} \mathrm{C}$ for $5 \mathrm{~h}$, to produce GN [37]. 


\subsection{Generation of VOCs in an Air Stream and their Collection by GN}

To generate a stream of air contaminated with selected VOCs, a $20 \mathrm{dm}^{3}$ dynamic chamber reported previously [18] was used. A dynamic temperature-controlled oven (Kin-Tek Laboratories Inc. model $491 \mathrm{M}-\mathrm{B}$ ) was used to generate constant concentrations of selected VOCs (toluene, ethylbenzene, cumene and dichlorobenzene) in air. Four gas chromatography (GC) autosampler vials (with silicone seal tops) were used to store $1 \mathrm{~cm}^{3}$ each of toluene, ethylbenzene (EB), cumene, or dichlorobenzene (DCB). The GC vials were pierced with a GC syringe needle (18 gauge) to provide a controlled permeation source, and the pierced vials were placed in the temperaturecontrolled oven. A constant air flow rate $\left(200 \mathrm{~cm}^{3} \mathrm{~min}^{-1}\right)$ passed over the VOC sources held at $25^{\circ} \mathrm{C}$. Under these conditions, the emission rates of toluene, $\mathrm{EB}$, cumene or $\mathrm{DCB}$ were calculated as $13,643,7221,4939$ or $3130 \mathrm{ng} \mathrm{min}^{-1}$, generating theoretical concentrations of $34.05,18.02,12.38$ or $7.81 \mathrm{mg} \mathrm{m}^{-3}$, respectively.

To extract the chosen VOCs from the contaminated air stream, tubes were packed with $100 \mathrm{mg}$ of GN. Prior to packing the GN was mixed with $150 \mathrm{mg}$ of glass beads (750$1000 \mu \mathrm{m}$ ) to allow air to flow through the GN loaded tube without generating an increased back pressure. The glass bead and sorbent mix was held in the tube with glass wool and wire gauze. These tubes will be hereafter referred to as 'sorbent tubes'. To ensure the glass beads, glass wool and wire gauze did not adsorb VOCs from the flowing air stream the VOC contaminated air stream was passed, at $100 \mathrm{~cm}^{3} \mathrm{~min}^{-1}$ for $1 \mathrm{~min}$, through a sorbent tube which did not contain GN but only glass beads. No VOCs were adsorbed by the blank sorbent tube containing only glass beads. The contaminated air stream was then passed through commercial sampling tubes containing $100 \mathrm{mg}$ of Tenax ${ }^{\mathrm{TM}} \mathrm{TA}$; the universal benchmark used in most dynamic air sampling campaigns. These tubes will hereafter be referred to as 'sampling tubes' and were prepared as described elsewhere [34]. Using a flow rate of $100 \mathrm{~cm}^{3} \mathrm{~min}^{-1}$ for 1 min average $(n=3)$ trapped masses of $2109,406,479$ or $495 \mathrm{ng}$, of toluene, EB, cumene or DCB with relative standard deviations (RSDs) of 1.0, 1.3, 3.1 or $6.4 \%$, respectively, were determined by TD-GC-MS. These masses will be referred to as 'mass nosorb '. Sorbent tubes containing GN were then placed immediately before the Tenax ${ }^{\mathrm{TM}}$ TA sampling tube and the experiment was repeated. The VOC masses trapped onto the Tenax ${ }^{\mathrm{TM}}$ TA sampling tube were again determined by calibration and mass losses were attributed to the adsorption of VOCs by GN. These masses will be

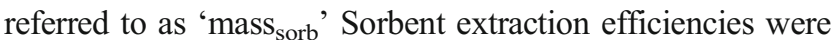
calculated as shown in the Eq. (1) below:

Extraction Efficiency $=\frac{\text { mass }_{\text {sorb }}}{\text { mass }_{\text {nosorb }}} \times 100 \%$

\subsubsection{Analysis of Tenax-TA Sampling Tubes by TD-GC-MS}

The masses of VOCs adsorbed by Tenax-TA sampling tubes were analysed using a Perkin Elmer Turbo Matrix thermal desorption unit (TDU), Perkin Elmer GC and Perkin Elmer Turbo Mass Gold mass spectrometer. VOCs were desorbed from sampling tubes by rapid heating to $300{ }^{\circ} \mathrm{C}$ for $5 \mathrm{~min}$ and desorbed VOCs were focused in an internal trap at $-30{ }^{\circ} \mathrm{C}$ before the trap was heated to $300^{\circ} \mathrm{C}$. An outlet split (5:95) was used to allow $5 \%$ of the trapped sample to pass onto the GC column. The eluate was diverted to the GC-MS using an inlet line temperature of $180^{\circ} \mathrm{C}$. A Perkin-Elmer, SMS Elite (dimethylpolysiloxane, 5\% diphenyl) $30 \mathrm{~m}$ ( $0.25 \mathrm{~mm}$ internal diameter) column was used and the oven was programmed with an initial temperature of $65^{\circ} \mathrm{C}$ for $5 \mathrm{~min}$ before heating to $90^{\circ} \mathrm{C}$ for $8 \mathrm{~min}$. Quantification of trapped masses was achieved using calibration: five sampling tubes were spiked with different volumes of a methanolic standard solutions introducing 100 $500 \mathrm{ng}$ masses of each analyte into each tube.

\subsection{Characterisation and Analysis}

To examine the pore ordering within the synthesised materials, X-ray diffraction (XRD) profiles were recorded on a Philips X'Pert Diffractometer equipped with a $\mathrm{Cu} \mathrm{K} \mathrm{K}_{\alpha}$ radiation source and accelerator detector. Incident and reflected Stoller slits of $0.2^{0}$ were used with a programmable divergent slit (a constant $10 \mathrm{~mm}$ sample footprint). To permit accurate low angle operation, a knife-edge was placed $0.3 \mathrm{~mm}$ above the centre of the sample to reduce low angle scattering. Care was also taken to place the sample surface at the axis of rotation of the goniometer and for this the sample was situated below the straight through beam and was raised slowly until a beam of intensity was attenuated by $50 \%$ compared to the straight through signal.

The specific surface area, average pore size and pore volume of GN were measured using nitrogen adsorptiondesorption isotherms using a Micromeritics ASAP 2420 instrument. Samples were degassed prior to the analysis for $6 \mathrm{~h}$ at $200{ }^{\circ} \mathrm{C}$. Experimental points obtained at a relative pressure $\left(p / p_{0}\right)$ of $0.05-0.25$ were used to calculate the BrunauerEmmett-Teller (BET) surface areas. A 30-point plot was used to calculate the average pore size distribution of the materials by using the Barret-Joyner-Halenda (BJH) model and the total pore volume was calculated at $p / p_{0}$ equal to 0.99 . Desorption isotherms were used to calculate the pore diameters. The micropore measurements were performed on a Quantachrome Autosorb-1, which measures equilibrium pressures after the addition or removal of nitrogen from the system. The measurements were made using the adsorption branch at minimum relative pressure of $10^{-5}$. Using nitrogen 
as the adsorbate allows pores down to $7 \AA$ to be measured, however, adsorption was found in pores smaller than this. Determination of their absolute diameter was not possible as the adsorption under these conditions does not represent completely covered surfaces due to the spatial constraints on the nitrogen molecules. The surface areas and volumes were determined by using the $t$-method of Halsey for micropore volume in the presence of mesopores:

$$
t(\AA)=a\left[\frac{1}{\ln \left(\frac{p_{0}}{p}\right)}\right]^{\frac{1}{b}}
$$

Where,

$$
\begin{array}{ll}
t & \text { statistical adsorbed film thickness } \\
a & \text { Pre-exponential term }=6.0533 \text { for nitrogen } \\
b & \text { Exponential term }=3.0 \text { for nitrogen } \\
p_{0} / p & \text { Relative pressure }
\end{array}
$$

Typically, materials with micropores and mesopores show two linear regions of monolayer formation where the intersection is a measure of the pore diameter $(2 t)$. The upper linear region represents the mesopore slope from which the mesopore surface can be determined using the above equation and the lower linear region represents the total pore slope. The micropore surface $S_{\mu}$ is the difference between the BET surface and the $t$ area $\mathrm{S}_{\mathrm{t}}$ :

$S_{\mu}=S_{B E T}-S_{t}$

\section{Results and Discussion}

Often benzene, toluene, ethylbenzene and xylene (BTEX) are chosen for such studies, however due to the carinogenic properties of benzene this target was not included here. Instead the study focussed on 4 typical indoor air pollutants with different vapour pressures, hydrophobicity and one which was chlorinated. The chosen analytes represent a cross-section of typical indoor air pollutants. The extraction efficiencies of GN or MCM-41 adsorbents were carefully investigated for four VOCs - toluene, EB, cumene and DCB. By studying high concentrations, the sorbents are shown to work for both indoor air remediation and industrial air clean up. Use of low concentrations was avoided as they might give a false impression of efficiency/ability of the chosen materials to remove pollutants in real environments. It was discovered that GN30-11 removed all four VOCs (Fig. 1a) with extraction efficiencies reaching over $60 \%$. These are similar to those reported for mesoporous silica [18], in spite of the lower surface area and low pore volume of GN (discussed below). This observation highlights the high selectivity of GN in VOC removal and strongly supports the potential of GN as greener alternatives of traditional porous materials.

Further experiments were conducted in order to examine the breakthrough and dynamic capacity of GN30-11 by passing an air stream, containing all 4 VOCs together, through the sorbent tubes ( $100 \mathrm{mg}$ of sorbent in each tube) at 100 $\mathrm{cm}^{3} \mathrm{~min}^{-1}$ for sampling times up to $120 \mathrm{~min}$. VOC passing through the sorbent tubes (i.e. not adsorbed) were collected and quantified using sampling tubes containing Tenax ${ }^{\mathrm{TM}} \mathrm{TA}$. The breakthrough values were calculated by taking the mass of VOC that passed through the sorbent tube unretained and dividing by the mass of VOC that was trapped by the sampling tube without any sorbent in-line. By convention, breakthrough was defined when percentage values were greater than $5 \%$. The general trend observed for all four VOCs suggested that for a fixed amount of sorbent $(100 \mathrm{mg})$, the capacities of GN30-11 ranged between 500 and 2500 ng (Fig. 1b). These appear to be lower than those reported for VOC adsorption using mesoporous silica [18]. It has been reported that breakthrough typically depends on the sorbent surface area [38]. It thus becomes clear that the lower surface area of GN30-11 $\left(58 \mathrm{~m}^{2} \mathrm{~g}^{-1}\right)$ contributes to its lower capacity.

Tailored GN materials were prepared by systematically varying the synthetic conditions in order to further investigate this interesting phenomenon. This resulted in four additional samples (Table 1) which were labelled GN $\alpha-\beta \gamma$, where $\alpha$ is the silicate precursor concentration used and $\beta: \gamma$ is the molar ratio of silicon to nitrogen. For example, a sample synthesised by using $20 \mathrm{mM}$ silicate and a $1: 2[\mathrm{Si}]$ to $[\mathrm{N}]$ ratio will be labelled GN20-12. The surface areas for these GN ranged from 49 to $363 \mathrm{~m}^{2} \mathrm{~g}^{-1}$ and their VOC extraction efficiencies and capacities were studied. Similar to GN30-11, these additional GN possessed VOC extraction efficiencies which were comparable to or slightly better than those reported for mesoporous silicas (Fig. 2a) [18]. In order to understand the relationship between the physical properties of these adsorbents with their functional performance, VOC extraction capacities were normalised with respect to their surface areas. Surprisingly, despite the low surface areas, the normalised capacity of GN ( $\left.80-450 \mathrm{ng} / \mathrm{m}^{2}\right)$ (Fig. 2b) were higher than those reported for mesoporous silicas $\left(50-150 \mathrm{ng} / \mathrm{m}^{2}\right)$ [18]. Since the GN presented herein exhibited a range of surface areas, the VOC extraction results indicate that the performance of all materials could only be loosely dependent on their surface areas, but without any direct correlation between surface area or pore volume with the observed capacities as seen in Fig. S1. These results suggest that there may be additional factors underpinning the VOC extraction.

In order to obtain further understanding of these results, the chemical properties of GN and other silica used in previous studies were compared. As both types of adsorbents were obtained by a solution process with an identical final calcination step used for removing the organic molecules, the surface 
Fig. 1 a Extraction efficiency and b capacity per $0.1 \mathrm{~g}$ sample for GN30-11 in VOC removal. T: toluene, EB: ethylbenzene, C: cumene and DCB:

dichlorobenzene
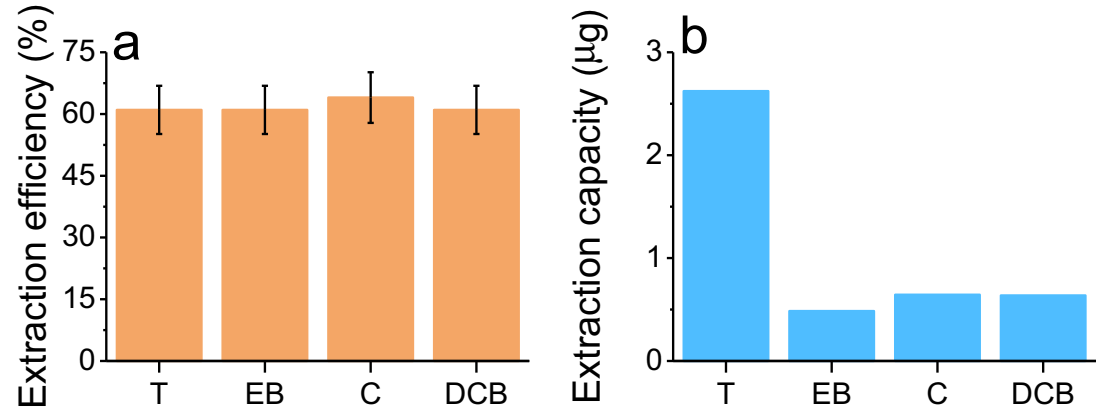

chemistries (i.e. the surface distribution of siloxane $\mathrm{Si}-\mathrm{O}-$ $\mathrm{Si}$, silanol $\mathrm{Si}-\mathrm{OH}$, and ionic siloxide $\mathrm{Si}-\mathrm{O}^{-}$groups) of these adsorbents are expected to be similar [34]. It is therefore reasonable to assume that chemical interactions between the VOCs and sorbents would not be different for each type of silica under consideration. However, there is a possibility of differences in pore sizes, pore size distribution and pore structure/ordering in the GN materials.

Nitrogen adsorption isotherms were recorded for the samples (Fig. 3a). MCM-41 typically has a narrow pore size distribution with an average pore size of 2-3 nm. The isotherm shape of the GN was thought to reflect combined features of type I and type II isotherms (Fig. 3a). The adsorption/ desorption isotherms show a significant adsorption of nitrogen at very low pressure consistent with the presence of micropores. The gradual slope between 0.1 and 0.8 shows the filling of non-specific diameter mesopores, resulting in very broad pore size distributions for GN (Fig. 3b). The large volume adsorbed between 0.9 and 1 represents the filling of the inter-particle spaces. The observation of microporosity of the GN is consistent with our previous reports on similar systems [33]. Further analysis using the $t$-method of Halsay was performed to decouple the microporosity from mesoporosity (see Experimental and Fig. S2 in Supporting Information for details). The micropore size was calculated as $7 \AA$, while the micropore surface area was determined to be $16 \%$ of the total surface area.

The possibility of pore ordering was assessed using Small Angle Scattering X-Ray Diffraction (SAS-XRD), Fig. 3c. The GN XRD patterns indicated that all of the newly prepared bioinspired materials were amorphous with no pore ordering, which is reminiscent of a network of branched pores. The lack of an ordered pore structure for the GN was further confirmed by Transmission Electron Microscopy (TEM), suggesting a random distribution of pores (pore size $\approx 0.25-1.5 \mathrm{~nm}$, formed between primary particles, Fig. 3d) consistent with the assignment of microporosity from the nitrogen adsorption measurements. Low resolution TEM data also revealed that the secondary particulates have a pseudo-spherical morphology with high levels of aggregation (Fig. S3). In addition to mesoporosity, the packing of these particles, which causes inter-particle porosity, explains the rather higher pore volume compared to the materials with only microporosity and, hence, further supports the nitrogen adsorption results.

It is highly likely that the unique combination of broad pore size distribution, disordered arrangement of pores and the presence of meso- and micro-porosity in GN contribute to their observed remarkable VOC extraction efficiencies
Table 1 Physical characterisation data for GNs

\begin{tabular}{llllll}
\hline Sample & {$[\mathrm{Si}] \mathrm{mM}$} & {$[\mathrm{Si}]:[\mathrm{N}]$} & Surface area $\left(\mathrm{m}^{2} \mathrm{~g}^{-1}\right)^{\mathrm{a}}$ & Pore size $(\mathrm{nm})^{\mathrm{b}}$ & Pore vol $\left(\mathrm{cm}^{3} \mathrm{~g}^{-1}\right)^{\mathrm{c}}$ \\
\hline GN30-11 & 30 & $1: 1$ & 58 & broad & 0.20 \\
GN30-12 & 30 & $1: 2$ & 49 & broad & 0.13 \\
GN30-21 & 30 & $2: 1$ & 355 & broad & 0.28 \\
GN20-11 & 20 & $1: 1$ & 363 & broad & 0.26 \\
GN40-11 & 40 & $1: 1$ & 260 & broad & 0.59 \\
\hline
\end{tabular}

${ }^{\text {a }}$ Calculated by BET model from sorption data in relative pressure range from 0.05 to 0.25

${ }^{\mathrm{b}}$ Calculated by BJH model from the adsorption branches of isotherm

${ }^{\mathrm{c}}$ Calculated from $\mathrm{N}_{2}$ amount adsorbed at a relative pressure $\mathrm{P} / \mathrm{P}_{0}$ of 0.99 . broad: no clear peak observed as can be seen in Fig. 3 
Fig. 2 a Extraction efficiency and b typical normalised capacity of GN in VOC removal
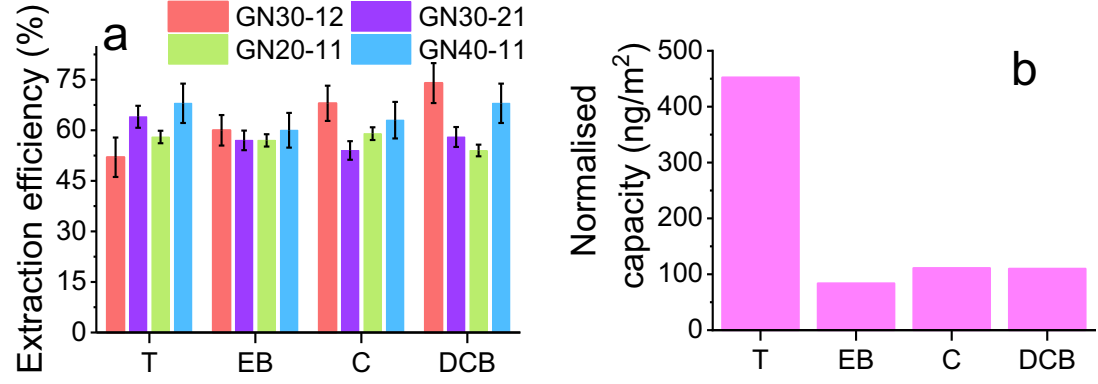

and selectivity. Diffusional access to the pores is governed by the pore size (e.g. increased diffusional access to micropores via mesoporous channels), the arrangement of the pores (e.g. interconnectivity) will combine to make any porous material a better adsorbent for gaseous molecules. Indeed, it has been reported that the presence of microporosity and interconnected pores strongly influence selective adsorption of aromatic VOCs through stronger interactions with micropores [39-42]. In particular, for porous silicas, textural properties have been shown to play a crucial role in VOC adsorption such that higher capacities can be achieved due to the presence of a bimodal meso- and micro-porosity $[25,43]$. These reports explain why the VOC selectivity of GN was significantly higher than that of mesoporous silicas. Further, this also suggests that silica gels or macroporous materials may be less suitable for removal of aromatic VOCs from air. However, further in-depth measurements and analysis of properties, economics and life-cycle will be required before fully comparing GN with other sorbents for VOC removal.

\section{Conclusions}

This work presents the production of novel silicas using a bioinspired green method. In the application of these materials for adsorption of VOCs, their performance was comparable or better with respect to benchmark mesoporous silica in terms of extraction efficiencies $(>60 \%)$ and capacity per unit surface area $\left(80-450 \mathrm{ng} / \mathrm{m}^{2}\right)$. The results suggest that the performance in VOC removal of the GN is related to their unique physical properties such as a network of micro- and meso-pores, which can be easily tailored. Furthermore, the preparation of GN exhibits the advantages including the use of neutral $\mathrm{pH}$ and room temperature conditions, rapid synthesis, and a substantial reduction in secondary pollution by the elimination of the
Fig. 3 a Nitrogen adsorption isotherm of GN30-11. b Pore size distribution and $\mathbf{c}$ SAS-XRD for GN. d Representative TEM image of GN
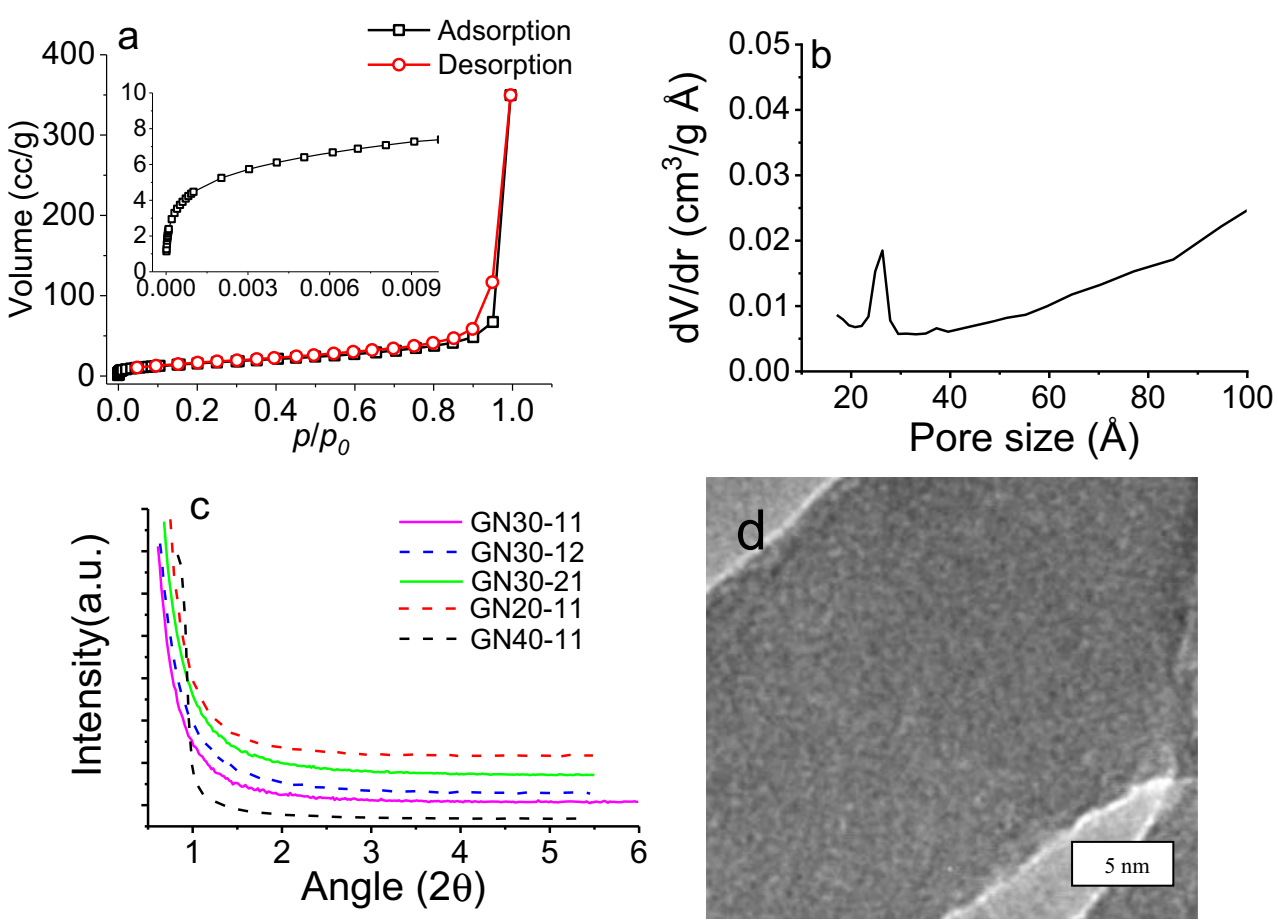
need for organic solvents from the preparation method. These advantages represent a significant progress since the complex and lengthy process of mesoporous silicas has been a major roadblock in delivering these materials to market in a costeffective manner. It is clear from the results presented herein that GN form a viable alternative to traditional porous materials in gas separation and their unique features could be advantageous in a number of other applications such as catalysis. By highlighting the strengths of GN, the present study also identifies future developments for GN including the need for further optimisation of synthetic conditions in order to improve physical properties such as surface area while retaining their unique pore structures.

Supplementary Information The online version contains supplementary material available at https://doi.org/10.1007/s12633-020-00924-1.

Acknowledgements We thank Al Marqab University (Libya), a 'Bridging the Gap' Award from the University of Strathclyde (for A. M. E.-A.) and EPSRC Fellowship (EP/R025983/1) for supporting this work.

Author Contributions Abdunaser M. Ewlad-Ahmed designed and performed the experiments, analysed the results and prepared a write-up.

Michael Morris and Justin Holmes performed the electron microscopy and X-ray diffraction.

David J. Belton performed the gas adsorption experiments and data analysis, and wrote relevant sections.

Siddharth V. Patwardhan and Lorraine T. Gibson designed and supervised the entire research, coordinated with authors, analysed the results, prepared figures and wrote the manuscript.

Funding See Acknowledgements above.

Data Availability Electronic supplementary material contains additional porosity and microscopy data.

\section{Compliance with Ethical Standards Not applicable.}

Conflict of Interest Authors declare no conflict of interest.

Consent to Participate Not applicable.

Consent for Publication In accordance with the copyright transfer or open access rules.

Open Access This article is licensed under a Creative Commons Attribution 4.0 International License, which permits use, sharing, adaptation, distribution and reproduction in any medium or format, as long as you give appropriate credit to the original author(s) and the source, provide a link to the Creative Commons licence, and indicate if changes were made. The images or other third party material in this article are included in the article's Creative Commons licence, unless indicated otherwise in a credit line to the material. If material is not included in the article's Creative Commons licence and your intended use is not permitted by statutory regulation or exceeds the permitted use, you will need to obtain permission directly from the copyright holder. To view a copy of this licence, visit http://creativecommons.org/licenses/by/4.0/.

\section{References}

1. Barton TJ, Bull LM, Klemperer WG, Loy DA, McEnaney B, Misono M, Monson PA, Pez G, Scherer GW, Vartuli JC, Yaghi OM (1999) Tailored porous materials. Chem Mater 11(10):26332656. https://doi.org/10.1021/Cm9805929

2. Davis ME (2002) Ordered porous materials for emerging applications. Nature 417(6891):813-821. https://doi.org/10.1038/ Nature00785

3. Stein A (2003) Advances in microporous and mesoporous solids highlights of recent progress. Adv Mater 15(10):763-775. https:// doi.org/10.1002/adma.200300007

4. Cassiers K, Linssen T, Mathieu M, Benjelloun M, Schrijnemakers K, Van Der Voort P, Cool P, Vansant EF (2002) A detailed study of thermal, hydrothermal, and mechanical stabilities of a wide range of surfactant assembled mesoporous silicas. Chem Mater 14(5):23172324. https://doi.org/10.1021/cm0112892

5. Zhao XS, Lu GQM, Millar GJ (1996) Advances in mesoporous molecular sieve MCM-41. Ind Eng Chem Res 35(7):2075-2090. https://doi.org/10.1021/ie950702a

6. Sayari A, Hamoudi S (2001) Periodic mesoporous silica-based organic - inorganic nanocomposite materials. Chem Mater 13(10): 3151-3168. https://doi.org/10.1021/cm0110391

7. Selvam P, Bhatia SK, Sonwane CG (2001) Recent advances in processing and characterization of periodic mesoporous MCM-41 silicate molecular sieves. Ind Eng Chem Res 40(15):3237-3261. https://doi.org/10.1021/ie0010666

8. Soler-Illia GJA, Sanchez C, Lebeau B, Patarin J (2002) Chemical strategies to design textured materials: from microporous and Mesoporous oxides to Nanonetworks and hierarchical structures. ChemRev 102(11):4093-4138. https://doi.org/10.1021/cr0200062

9. Beck JS, Calabro DC, Mccullen SB, Pelrine BP, Schmitt KD, Vartuli JC (1992) Method for functionalizing synthetic mesoporous crystalline material. US 5,145,816

10. Cauvel A, Renard G, Brunel D (1997) Monoglyceride synthesis by heterogeneous catalysis using MCM-41 type silicas functionalized with amino groups. J Organomet Chem 62(3):749-751. https://doi. org/10.1021/jo9614001

11. Fowler CE, Burkett SL, Mann S (1997) Synthesis and characterization of ordered organo-silica-surfactant mesophases with functionalized MCM-41-type architecture. Chem Commun 18:17691770. https://doi.org/10.1039/a704644h

12. Lim MH, Blanford CF, Stein A (1997) Synthesis and characterization of a reactive vinyl-functionalized MCM-41: probing the internal pore structure by a bromination reaction. J Am Chem Soc 119(17):4090-4091. https://doi.org/10.1021/ja9638824

13. Kresge CT, Leonowicz ME, Roth WJ, Vartuli JC, Beck JS (1992) Ordered mesoporous molecular-sieves synthesized by a liquidcrystal template mechanism. Nature 359(6397):710-712

14. Grun M, Unger KK, Matsumoto A, Tsutsumi K (1999) Novel pathways for the preparation of mesoporous MCM-41 materials: control of porosity and morphology. Microporous Mesoporous Mater 27(2-3):207-216. https://doi.org/10.1016/s1387-1811(98)00255-8

15. Huang Z, Huang L, Shen SC, Poh CC, Hidajat K, Kawi S, Ng SC (2005) High quality mesoporous materials prepared by supercritical fluid extraction: effect of curing treatment on their structural stability. Microporous Mesoporous Mater 80(1-3):157-163. https://doi. org/10.1016/j.micromeso.2004.12.016

16. Pan D, Tan L, Qian K, Zhou L, Fan Y, Yu C, Bao X (2010) Synthesis of highly ordered and hydrothermally stable mesoporous materials using sodium silicate as a precursor. Mater Lett 64(13): 1543-1545. https://doi.org/10.1016/j.matlet.2010.03.072 
17. Walcarius A, Mercier L (2010) Mesoporous organosilica adsorbents: nanoengineered materials for removal of organic and inorganic pollutants. J Mater Chem 20(22):4478. https://doi.org/10. 1039/B924316j

18. Idris SA, Robertson C, Morris MA, Gibson LT (2010) A comparative study of selected sorbents for sampling of aromatic VOCs from indoor air. Anal Methods 2(11):1803. https://doi.org/10. 1039/c0ay00418a

19. Zabiegala B, Partyka M, Zygmunt B, Namiesnik J (2009) Determination of volatile organic Compounds in indoor air in the Gdansk area using permeation passive samplers. Ind Built Environ 18(6):492-504. https://doi.org/10.1177/1420326x09336550

20. Solomon SJ, Schade GW, Kuttippurath J, LadstaetterWeissenmayer A, Burrows JP (2008) VOC concentrations in an indoor workplace environment of a university building. Ind Built Environ 17(3):260-268. https://doi.org/10.1177/ 1420326x08090822

21. Heroux M-E, Gauvin D, Gilbert NL, Guay M, Dupuis G, Legris M, Levesque B (2008) Housing characteristics and indoor concentrations of selected volatile organic compounds (VOCs) in Quebec City, Canada. Ind Built Environ 17(2):128-137. https://doi.org/ 10.1177/1420326x07089005

22. Abdullah MO, Tan IAW, Lim LS (2011) Automobile adsorption air-conditioning system using oil palm biomass-based activated carbon: a review. Renew Sust Energ Rev 15(4):2061-2072. https://doi.org/10.1016/j.rser.2011.01.012

23. Delaney P, Healy RM, Hanrahan JP, Gibson LT, Wenger JC, Morris MA, Holmes JD (2010) Porous silica spheres as indoor air pollutant scavengers. J Environ Monit 12(12):2244-2251. https:// doi.org/10.1039/c0em00226g

24. Berg F, Gohlke K, Pasel C, Luckas M, Eckardt T, Bathen D (2018) Single and binary mixture adsorption behaviors of C-6-C-8 hydrocarbons on silica-alumina gel. Ind Eng Chem Res 57(48):1645116463. https://doi.org/10.1021/acs.iecr.8b04498

25. Emparan-Legaspi MJ, Gonzalez J, Gonzalez-Carrillo G, CeballosMagana SG, Canales-Vazquez J, Aguayo-Villarreal IA, MunizValencia R (2020) Dynamic adsorption separation of benzene/ cyclohexane mixtures on micro-mesoporous silica SBA-2. Microporous Mesoporous Mater 294:109942. https://doi.org/10. 1016/j.micromeso.2019.109942

26. Gelles T, Krishnamurthy A, Adebayo B, Rownaghi A, Rezaei F (2020) Abatement of gaseous volatile organic compounds: a material perspective. Catal Today 350:3-18. https://doi.org/10.1016/j. cattod.2019.06.017

27. Forsyth C, Patwardhan SV (2013) Controlling performance of lipase immobilised on bioinspired silica. J Mater Chem B 1:1164 1174

28. Patwardhan SV, Manning JRH, Chiacchia M (2018) Bioinspired synthesis as a potential green method for the preparation of nanomaterials: opportunities and challenges. Curr Opin Green Sust 12:110-116. https://doi.org/10.1016/j.cogsc.2018.08.004

29. Patwardhan SV, Staniland SS (2019) Green Nanomaterials. From bioinspired synthesis to sustainable manufacturing of inorganic nanomaterials. IOP. https://doi.org/10.1088/978-0-7503-1221-9

30. Patwardhan SV (2011) Biomimetic and bioinspired silica: recent developments and applications. Chem Commun 47(27):75677582. https://doi.org/10.1039/c0cc05648k
31. Patwardhan SV, Clarson SJ, Perry CC (2005) On the role(s) of additives in bioinspired silicification. Chem Commun 9:11131121. https://doi.org/10.1039/b416926c

32. Belton DJ, Patwardhan SV, Annenkov VV, Danilovtseva EN, Perry CC (2008) From biosilicification to tailored materials: optimizing hydrophobic domains and resistance to protonation of polyamines. Proc Natl Acad Sci U S A 105(16):5963-5968. https://doi. org/10.1073/pnas.0710809105

33. Belton DJ, Patwardhan SV, Perry CC (2005) Spermine, spermidine and their analogues generate tailored silicas. J Mater Chem 15(43): 4629-4638. https://doi.org/10.1039/b509683a

34. Ewlad-Ahmed AM, Morris MA, Patwardhan SV, Gibson LT (2012) Removal of formaldehyde from air using functionalized silica supports. Environ Sci Technol 46:13354-13360

35. Manning JRH, Routoula E, Patwardhan SV (2018) Preparation of functional silica using a bioinspired method. J Vis Exp 138:57730. https://doi.org/10.3791/57730

36. Patwardhan SV, Manning JRH (2015) Silica synthesis. WO/2017/ 037460

37. We have invented and patented a room temperature solution method without needing calcination for template removal (Eco-friendly and scalable method for pure and porous silica, PCT/GB2016/ 052705). The reason we did not use that route in this paper and instead used calcination was to allow consistency with postsynthetic treatments between our silica and MCM-052741 reported in the literature in order to offer a clear comparison. It is known that the surface chemistry of silica is different for samples obtained from calcination in comparison with those obtained from solution methods (difference in surface silanol groups, which affect adsorption behaviours)

38. Foster KL, Fuerman RG, Economy J, Larson SM, Rood MJ (1992) Adsorption characteristics of trace volatile organic-compounds in gas streams onto activated carbon-fibers. Chem Mater 4(5):10681073. https://doi.org/10.1021/cm00023a026

39. Zhang W, Qu Z, Li X, Wang Y, Ma D, Wu J (2012) Comparison of dynamic adsorption/desorption characteristics of toluene on different porous materials. J Environ Sci (China) 24(3):520-528. https:// doi.org/10.1016/s1001-0742(11)60751-1

40. Lillo-Rodenas MA, Fletcher AJ, Thomas KM, Cazorla-Amoros D, Linares-Solano A (2006) Competitive adsorption of a benzenetoluene mixture on activated carbons at low concentration. Carbon 44(8):1455-1463. https://doi.org/10.1016/j.carbon.2005. 12.001

41. Fletcher AJ, Yuzak Y, Thomas KM (2006) Adsorption and desorption kinetics for hydrophilic and hydrophobic vapors on activated carbon. Carbon 44(5):989-1004. https://doi.org/10.1016/j.carbon. 2005.10.020

42. Ueno Y, Tate A, Niwa O, Zhou HS, Yamada T, Honma I (2004) High benzene selectivity of uniform sub-nanometre pores of selfordered mesoporous silicate. Chem Commun (6):746-747. https:// doi.org/10.1039/B316799b

43. Kosuge K, Kubo S, Kikukawa N, Takemori M (2007) Effect of pore structure in Mesoporous Silicas on VOC dynamic adsorption/desorption performance. Langmuir 23(6):3095-3102. https://doi.org/10.1021/la062616t

Publisher's Note Springer Nature remains neutral with regard to jurisdictional claims in published maps and institutional affiliations. 